\title{
Screening for Residual Disease in Pediatric Burkitt Lymphoma Using Consensus Primer Pools
}

\author{
Melissa Agsalda, ${ }^{1}$ Ian Kusao, ${ }^{2}$ David Troelstrup, ${ }^{3}$ and Bruce Shiramizu ${ }^{3}$ \\ ${ }^{1}$ Department of Cell \& Molecular Biology, John A. Burns School of Medicine, University of Hawaii, Honolulu, HI 96816, USA \\ ${ }^{2}$ Department of Physiology, John A. Burns School of Medicine, University of Hawaii, Honolulu, HI 96816, USA \\ ${ }^{3}$ Department of Pediatrics \& Medicine, John A. Burns School of Medicine, University of Hawaii, Honolulu, HI 96816, USA
}

Correspondence should be addressed to Bruce Shiramizu, bshirami@hawaii.edu

Received 30 December 2008; Accepted 25 January 2009

Recommended by Thomas G. Gross

\begin{abstract}
Assessing molecular persistent or minimal residual disease (PD/MRD) in childhood Burkitt lymphoma (BL) is challenging because access to original tumor is usually needed to design patient-specific primers (PSPs). Because BL is characterized by rearranged immunoglobulin heavy chain $\left(\mathrm{IgV}_{\mathrm{H}}\right)$ genes, $\mathrm{IgV}_{\mathrm{H}}$ primer pools from $\mathrm{IgV}_{\mathrm{Hl}}-\mathrm{IgV}_{\mathrm{H}}$ regions were tested to detect $\mathrm{PD} / \mathrm{MRD}$, thus eliminating the need for original tumor. The focus of the current study was to assess the feasibility of using $\operatorname{IgV}_{\mathrm{H}}$ primer pools to detect disease in clinical specimens. Fourteen children diagnosed with B-NHL had follow-up repository specimens available to assess $\mathrm{PD} / \mathrm{MRD}$. Of the 14 patients, 12 were $\mathrm{PD} / \mathrm{MRD}$ negative after 2 months of therapy and remained in remission at the end of therapy; 2/14 patients were PD/MRD positive at 2-3 months and later relapsed. PSP-based assays from these 14 patients showed $100 \%$ concordance with the current assay. This feasibility study warrants further investigation to assess PD/MRD using $\mathrm{IgV}_{\mathrm{H}}$ primer pools, which could have clinical significance as a real-time assessment tool to monitor pediatric BL and possibly other B-cell non-Hodgkin lymphoma therapy.
\end{abstract}

Copyright (C) 2009 Melissa Agsalda et al. This is an open access article distributed under the Creative Commons Attribution License, which permits unrestricted use, distribution, and reproduction in any medium, provided the original work is properly cited.

\section{Introduction}

The prognosis for children diagnosed with Burkitt lymphoma (BL) has improved dramatically over the last decade; however a significant percentage (30-40\%) of children with advanced disease remain unresponsive to or relapse during therapy, particularly those with B-cell non-Hodgkin lymphoma (NHL) [1-3]. Because the prognosis for children who relapse during therapy is dismal, with an estimated 2 -year overall survival of $10-30 \%$, improvements in early detection of disease may improve their overall disease-free survival [2]. In such cases, identifying persistent disease or minimal residual disease (PD/MRD) could be important if the paradigm of early intervention when $\mathrm{PD} / \mathrm{MRD}$ is found can be translated from other pediatric cancers such as acute lymphoblastic leukemia [4].

Malignant BL cells are usually characterized with immunoglobulin heavy chain variable region $\left(\operatorname{IgV}_{\mathrm{H}}\right)$ gene rearrangements. The $\mathrm{IgV}_{\mathrm{H}}$ is formed during normal B-cell ontogeny by an ordered process of Ig gene rearrangement through assembling distinct variable $(\mathrm{V})$, diversity $(\mathrm{D})$, and joining $(\mathrm{J})$ gene segments known as VDJ recombination [5]. A single $V_{H}$ gene is chosen from the available $V_{H}$ repertoire consisting of $>50$ potentially functional genes that are grouped into 7 structurally related families $\left(\mathrm{V}_{\mathrm{H} 1-7}\right)[6]$. Rearrangements of $\mathrm{V}_{\mathrm{H}}$ genes can be exploited by analyzing the $\mathrm{V}_{\mathrm{H} 1-7}$ regions using polymerase chain reaction (PCR). We and others previously used this molecular fingerprint from NHL primary diagnostic tissue to detect PD/MRD in followup specimens [7-9]. However, as a clinical tool, identifying patient-specific primers (PSPs) designed from primary diagnostic tissue is labor-intensive and may not be applicable for real-time applications [7]. When faced with limited amount of tissue at the time of diagnosis, particularly from children, there may not be enough tissue available to design PSP if PD/MRD studies are to be tested [10-12]. The current study hypothesizes that detection of $\mathrm{PD} / \mathrm{MRD}$ in BL cases may be accomplished by more efficient means and not require primary diagnostic tissue to design unique PSP. Instead, PD/MRD assessment could be achieved with 
primer pools made up of $\mathrm{IgV}_{\mathrm{H}}$ oligomers from respective $\mathrm{V}_{\mathrm{H} 1}$ to $\mathrm{V}_{\mathrm{H} 7}$ families. Thus a strategy was designed to detect $\mathrm{PD} / \mathrm{MRD}$ with consensus primer pools by real-time PCR [7]. We report data using the primer pool method and compare results previously reported by our lab using PSPs [13].

\section{Methods and Materials}

The study focused on the feasibility of using pools of oligomers comprised of primers from the seven $V_{H}$ regions $\left(\mathrm{V}_{\mathrm{H} 1-7}\right)$ to amplify a clonal immunoglobulin heavy chain rearrangement that would be characteristic of BL cells by real-time PCR. The study, which was approved by the Institutional Review Board, analyzed repository specimens and compared against previous results in which the specimens were characterized using PSPs.

2.1. Patients and Specimens. Fourteen children with Burkitt lymphoma (BL) and known clinical outcomes had specimens available which were previously analyzed using PSP [7]. The diagnoses and staging were confirmed through a central review mechanism [7]. DNA from primary diagnostic tumor tissues and staging/followup specimens (peripheral blood mononuclear cells, PBMCs; bone marrow aspirate, BMA; cerebrospinal fluid, CSF) were available from paraffinembedded diagnostic tissue, unstained peripheral blood smears/bone marrow slides, and CSF cell pellets; see Table 1 [7]. DNA was assessed by ultraviolet spectrophotometry and by amplification with beta-globin primers, which showed adequate quantity and quality for PCR [13]. Specimens were from entry (diagnostic) and followup time points (1-month and 2-month postinduction chemotherapy); see Table 1. From the primary diagnostic tumor tissue, PSPs were designed and used to assess $\mathrm{PD} / \mathrm{MRD}$ on followup specimens as previously reported [7].

2.2. Real-Time PCR Using $V_{\mathrm{H} 1}-V_{\mathrm{H} 7}$ Primer Pools and Sensitivity Assessment. Groups of $5^{\prime}$-primers from the FR1 region of the variable $\mathrm{IgH}$ regions, $\mathrm{V}_{\mathrm{H} 1}-\mathrm{V}_{\mathrm{H} 7}$ (Operon Biotechnologies, Inc, Huntsville, AL, USA) were combined to form primer pools: $\mathrm{V}_{\mathrm{H} 1}, \mathrm{~V}_{\mathrm{H} 2}, \mathrm{~V}_{\mathrm{H} 3}, \mathrm{~V}_{\mathrm{H} 4}, \mathrm{~V}_{\mathrm{H} 5}, \mathrm{~V}_{\mathrm{H} 6}$, and $\mathrm{V}_{\mathrm{H} 7}$ (Table 2) identified through VBASE23 (http://vbase.mrc-cpe.cam.ac.uk/) [14]. Primers were designed from the FR1 region because of future plans to use the assay on DNA extracted from fresh or unstained slides of PBMC, BMA, and CSF. The two consensus $3{ }^{\prime}$-primers were: LJH and VLJH [7]. Seminested real-time PCR was performed in triplicate using an iCycler (BioRad Laboratories, Hercules, CA, USA), and StepOnePlus (Applied Biosystems, Foster City, CA, USA). The PCR parameters were optimized initially with DNA from a Bcell NHL cell line, Ramos (ATCC, Manassas, VA, USA) by diluting control human PBMC DNA as noted below with negative and positive controls consisting of peripheral blood mononuclear cells (PBMCs), water, and BL tumor DNA. The primer pool concentrations of $10 \mathrm{pmol}$ were found to be optimal with the PCR mix of 2x iQ SYBR Green Supermix (Biorad Laboratories, Hercules, CA, USA), 10 pmol 5' $5^{\prime} \operatorname{IgV}_{\mathrm{H}}$ primer pools and $10 \mathrm{pmol} 3^{\prime}$-primer $(\mathrm{LJH})$ and parameters: $95^{\circ} \mathrm{C} / 3$ minutes; 35 cycles $95^{\circ} \mathrm{C} / 10$ seconds, $60^{\circ} \mathrm{C} / 30$ seconds; $72^{\circ} \mathrm{C} / 3$ minutes; final extension of $72^{\circ} \mathrm{C} / 3$ minutes. PCR products were purified using ExoSAP-it (USB Corp, Cleveland, Ohio, USA), and recovered in $10 \mu \mathrm{L}$. An aliquot of $1 \mu \mathrm{L}$ was used for second-round PCR with 10 pmol $5^{\prime}$-primer pools and 10 pmol $3^{\prime}$-primer (VLJH). Following thresholddependent cycling, melting was performed from 60 to $95^{\circ} \mathrm{C}$ at either $0.5^{\circ} \mathrm{C} / \mathrm{s}$ or $0.1^{\circ} \mathrm{C} / \mathrm{s}$ melt rates with a smooth curve setting averaging 1 point with minor modifications of a previously described strategy to identify unique amplified products $[9,15]$. Melt curves were plotted as the negative first derivative of decrease in fluorescence versus temperature $(-\mathrm{dF} /-\mathrm{dT})$. Polyclonal products of different lengths would melt at different temperatures and displayed as broad peaks. A wide melt curve peak defined as the width at half height $\geq$ peak height was considered a negative result modified from previous reports due to different primers and compensations made in the current real-time methodology versus the plate reader assay $[16,17]$. Thus a positive (peak height $\geq$ width at half height); negative (peak height $\leq$ width at half height) or equivocal (multiple peaks) determination was established for each melt curve, (Figure 1) with verification by resolving the amplified products on agarose gels and sequencing, if appropriate. Differentiation by melt-curve analysis led to distinct melt temperatures for distinct amplified products if a unique $V_{H}$ region is amplified and represented as a sharp peak $[18,19]$. Following PCR, samples were subjected to two melt runs, with melt rates of either 0.1 or $0.5^{\circ} \mathrm{C} / \mathrm{s}$ if melt peaks could not be distinguished [20]. As noted by others, increasing the melt rate can increase the size of the melt peaks due to a more rapid loss of fluorescence, facilitating more reliable detection of weaker amplicons [20]. Sharp melt peaks corresponded to monoclonal bands while widened or flat melt curves suggested polyclonal or no clonal DNA, Figures $1(\mathrm{~b})$ and 1(c). If a melt curve suggested polyclonality, PCR products were purified and sequenced. For the current study, polyclonality determined by the sequence data was interpreted as negative for MRD/PD.

An algorithm was established to screen for $\mathrm{V}_{\mathrm{H}}$ family usage. In this study, each primary tumor tissue DNA was subjected to each of the following combinations of primer pools: $\mathrm{V}_{\mathrm{H} 1} \& \mathrm{~V}_{\mathrm{H} 2} ; \mathrm{V}_{\mathrm{H} 3} \& \mathrm{~V}_{\mathrm{H} 4} ; \mathrm{V}_{\mathrm{H} 5}, \mathrm{~V}_{\mathrm{H} 6}, \& \mathrm{~V}_{\mathrm{H} 7}$. The strategy allowed for combinations of $\mathrm{V}_{\mathrm{H}}$ primers to be used to screenin or screen-out involvement of variable regions. If particular primer pools were positive, then individual $\mathrm{V}_{\mathrm{H}}$ primers were used to individually retest the tumor tissue DNA to identify the variable region involved. The specific $\mathrm{V}_{\mathrm{H}}$ primer was then used to assess $\mathrm{PD} / \mathrm{MRD}$ on sequential specimens from the same patient. Sensitivity of the assay was determined by two methods using cell line DNA and BL tumor DNA. DNA from the B-cell NHL Ramos cell line and control human PBMC were combined in various dilutions (DNA equivalent of 1 Ramos cell to $10^{2}, 10^{3}, 10^{5}, 10^{7}, 10^{8}$, and $10^{9}$ PBMC DNA) to test the $\operatorname{IgV}_{\mathrm{H}}$ primer pools [21]. Dilutions of DNA from tumor DNA were prepared with control human PBMC to the DNA equivalent of 1 malignant cell to $10^{3}, 10^{5}, 10^{6}, 10^{8}$, and $10^{9}$ PBMC DNA. Each dilution was then assayed using $\mathrm{V}_{\mathrm{H} 4}$ primer, which was a characteristic of that particular tumor specimen. 
TABLE 1: Persistent or minimal residual disease assessment using real-time and PSP assays.

\begin{tabular}{|c|c|c|c|c|c|}
\hline \multirow{2}{*}{ Case (Dx) } & \multicolumn{5}{|c|}{ Real-time results/PSP results \& clinical status* } \\
\hline & Entry & $1 \mathrm{Mo}$ & $2 \mathrm{Mo}$ & 3-4 Mo & Clinical status \\
\hline \multirow{2}{*}{ NHL-1 (BL) } & Tissue (+/PSP) & & & & CR (End of $\mathrm{Rx}))$ \\
\hline & Blood $(+/+)$ & Blood $(-/-)$ & Blood $(+/+)$ & Blood $(-/-)$ & \\
\hline \multirow{3}{*}{ NHL-2 (BL) } & Tissue (+/PSP) & & & & CR (End of Rx) \\
\hline & Blood $(+/+)$ & Blood $(+/+)$ & & Blood $(-/-)$ & \\
\hline & $\operatorname{BMA}(+/+)$ & & & & \\
\hline \multirow{3}{*}{ NHL-3 (BL) } & Tissue (+/PSP) & & & & Dead (Infection; 3 mo) \\
\hline & Blood $(+/+)$ & Blood $(+/+)$ & & & \\
\hline & $\operatorname{BMA}(+/+)$ & & $\operatorname{BMA}(-/-)$ & & \\
\hline \multirow{2}{*}{ NHL-4 (BL) } & Tissue (+/PSP) & & & & CR ( End of Rx ) \\
\hline & Blood $(+/+)$ & Blood $(+/+)$ & $\operatorname{Blood}(-/-)$ & & \\
\hline \multirow{3}{*}{ NHL-5 (BL) } & Tissue (+/PSP) & & & & BMA relapse $(6 \mathrm{mo})$ \\
\hline & Blood (+/+) & Blood $(-/-)$ & & & \\
\hline & $\operatorname{BMA}(+/+)$ & $\operatorname{BMA}(+/+)$ & & & \\
\hline \multirow{2}{*}{ NHL-6 (BL) } & Tissue (+/PSP) & & & & CR ( End of Rx ) \\
\hline & $\operatorname{BMA}(+/+)$ & $\operatorname{BMA}(-/-)$ & & & \\
\hline \multirow{2}{*}{ NHL-7 (BL) } & Tissue (+/PSP) & & & & BMA relapse (3 mo) \\
\hline & $\operatorname{BMA}(+/+)$ & $\operatorname{BMA}(+/+)$ & & & \\
\hline \multirow{2}{*}{ NHL-8 (BL) } & Tissue (+/PSP) & & & & \\
\hline & Blood (+/+) & Blood $(-/-)$ & Blood $(-/-)$ & & CR (End of Rx) \\
\hline \multirow{3}{*}{ NHL-9 (BL) } & Tissue (+/PSP) & & & & \\
\hline & Blood (+/+) & Blood $(+/+)$ & & Blood $(-/-)$ & CR (End of Rx) \\
\hline & $\operatorname{CSF}(+/+)$ & & & $\operatorname{CSF}(=/=)$ & \\
\hline \multirow{2}{*}{ NHL-10 (BL) } & Tissue (+/PSP) & & & & \\
\hline & Blood (+/+) & & & Blood $(-/-)$ & CR (End of Rx) \\
\hline \multirow{2}{*}{ NHL-11 (BL) } & Tissue (+/PSP) & & & & \\
\hline & Blood (+/+) & Blood $(+/+)$ & Blood $(+/+)$ & Blood $(-/-)$ & CR (End of Rx) \\
\hline \multirow{4}{*}{ NHL-12 (BL) } & Tissue (+/PSP) & & & & \\
\hline & Blood $(+/+)$ & Blood (+/+) & Blood (-/-) & & CR (End of Rx) \\
\hline & BMA (Equiv) & BMA (+/+) & BMA $(-/-)$ & & \\
\hline & $\operatorname{CSF}(+/+)$ & & & & \\
\hline \multirow{4}{*}{ NHL-13 (BL) } & Tissue (+/PSP) & & & & \\
\hline & Blood (+/+) & Blood $(=/=)$ & Blood (=/=) & & \\
\hline & $\operatorname{BMA}(+/+)$ & & & $\operatorname{BMA}(-/-)$ & CR (End of Rx) \\
\hline & & & & $\operatorname{CSF}(-/-)$ & \\
\hline \multirow{3}{*}{ NHL-14 (BL) } & Tissue (+/PSP) & & & & \\
\hline & Blood $(+/+)$ & Blood $(-/-)$ & & Blood $(-/-)$ & CR (End of Rx) \\
\hline & $\operatorname{BMA}(+/+)$ & & & & \\
\hline
\end{tabular}

*Specimens were not available from some time points; Dx: diagnosis; BL: Burkitt lymphoma; BMA: bone marrow aspirate; real-time results/patient-specific primer (PSPs) results: Positive (+), Negative (-), or Equivocal (=) for each assay result; CR: complete remission; End of Rx: End of therapy.

\section{Results}

3.1. Real-Time PCR Using $V_{\mathrm{H} 1}-V_{\mathrm{H} 7}$ Primer Pools and Sensitivity Assessment. Dilutions of DNA from the control Ramos cell line were assayed using the $\mathrm{IgV}_{\mathrm{H}}$ primer pools [22]. Melt curve analysis of each reaction was plotted as the negative first derivative of decrease in fluorescence with respect to temperature $(-\mathrm{dF} / \mathrm{dT})$ and interpreted: Positive (distinct peak with minimal or no shoulder); Negative (broad peak); or Equivocal (multiple peaks with significant shoulder); see Figure 1. The dilution experiments demonstrated that Ramos cells could be detected on the order of 1 in $10^{5}$ to 1 in $10^{6}$ PBMC. Using patient tumor DNA, the sensitivity of the assay could detect malignant cells as low as 1 in $10^{5}$ PBMC (Figure 2).

$\mathrm{PD} / \mathrm{MRD}$ assays were performed on clinical specimens from the 14 subjects in which primary diagnostic tissues were available. The results were compared to the analyses from the PSP method and found 100\% concordance in that when $\mathrm{PD} / \mathrm{MRD}$ was positive via PSP method, the same result was 
TABle 2: Primers sequences.

\begin{tabular}{ll}
\hline Primer & Sequence $\left(5^{\prime}-3^{\prime}\right)$ \\
\hline VH1a & CAG GT(GT) CAG CTG GTG CAG \\
VH1b & CAG GTC CAG CTT GTG CAG \\
VH1c & (GC)AG GTC CAG CTG GTA CAG \\
VH1d & CA(AG) ATG CAG CTG GTG CAG \\
VH2a & CAG ATC ACC TTG AAG GAG \\
VH2b & CAG GTC ACC TTG A(AG)G GAG \\
VH3a & GA(AG) GTG CAG CTG GTG GAG \\
VH3b & CAG GTG CAG CTG GTG GAG \\
VH3c & GAG GTG CAG CTG TTG GAG \\
VH4a & CAG (CG)TG CAG CTG CAG GAG \\
VH4b & CAG (CG)TG CAG CTG CAG GAG \\
VH5a & GA(AG) GTG CAG CTG GTG CAG \\
VH6a & CAG GTA CAG CTG CAG CAG \\
VH7a & CAG GT(CG) CAG CTG GTG CAA \\
LJH & TGA GGA GAC GGT GAC C \\
VLJH & GTG ACC AGG GNC CTT GGC CCC AG \\
B-globin (forward) & GAA GAG CCA AGG ACA GGT AC \\
B-globin (reverse) & CAA CTT CAT CCA CGT TCA CC \\
\hline
\end{tabular}

obtained using $\operatorname{IgV}_{\mathrm{H}}$ primer pools (Table 1) [7]. The amplified products from the positive $\mathrm{PD} / \mathrm{MRD}$ specimens were sequenced, confirming the monoclonality of the specimens.

Patients, NHL-5 and NHL-7, continued to have PD/ MRD in followup BMA specimens 2 months after starting chemotherapy, and subsequently developed clinically detectable relapse at 6 months and 3 months, respectively. The amplified products from the BMA from these two subjects were purified and sequenced, which confirmed the same clone as the original primary diagnostic tumor. The other 12 cases demonstrated clearance of their followup blood and/or bone marrow specimens and at the end of therapy, remained in clinical remission. While no followup specimens were available from patients NHL-5 and NHL-7, the specimens which were positive for PD/MRD did not have evidence of disease by standard microscopic pathology.

To determine the utility of the methodology in assessing $\mathrm{PD} / \mathrm{MRD}$ in specimens when primary diagnostic tissues were not available, staging (Entry) specimens from each of the cases were assayed using $\mathrm{IgV}_{\mathrm{H}}$ primer pools using the same strategy noted above. Each subject had staging specimens which were positive for PD/MRD by a primer pool (Table 1). This was important to verify, to validate the use of the strategy in cases in which primary tumor tissue was not available.

\section{Discussion}

The current study was designed to assess PD/MRD on followup specimens from pediatric B-NHL cases regardless of whether primary diagnostic tissue was available from the time of diagnosis. We hypothesized that $\mathrm{PD} / \mathrm{MRD}$ could be screened in specimens using primer pools made up of $\operatorname{Ig} V_{\mathrm{H}}$ oligomers from respective $\mathrm{V}_{\mathrm{H}}$ to $\mathrm{V}_{\mathrm{H}}$ families. The method was compared to a previous study, which used the PSPbased assay, and the results demonstrated $100 \%$ concordance
[7]. Sequencing of the amplified products from primary diagnostic tumor DNA confirmed the results from the $\mathrm{V}_{\mathrm{H}}$ oligomer amplified product demonstrating that monoclonal results were represented by both methods.

The use of $\mathrm{IgV}_{\mathrm{H}}$ primer pools to screen for PD/MRD in clinical specimens was shown to have potential and feasibility. The current study is limited by the number of subjects and specimens available; however, as a feasibility study, the data support future consideration of the tool to determine the clinical significance of $\mathrm{PD} / \mathrm{MRD}$ in pediatric BL and possibly B-cell NHL therapy trials. A potential limitation of the approach describe in this paper is that the $\mathrm{BL}$ clone needs to have rearrangement of an $\mathrm{IgH}$ gene [23]. Thus in BL cases involving immunoglobulin light chain rearrangements, the primer pools will need to be redesigned $[23,24]$. There is precedence for potential utility of real-time assessment of PD/MRD. PCR-based MRD assays have been tested clinically in childhood acute lymphoblastic leukemia (ALL) by targeting IgH gene rearrangements with sensitivities on the order of one leukemic cell in $10^{4}-10^{6}$ normal cells. Rapid reduction of MRD following induction therapy was associated with a 3-year relapse rate less than $5 \%$, while children with detectable MRD had a 3-year relapse rate of $23 \%-75 \%$ [25]. In ALL, MRD was the most powerful prognostic factor of outcome, independent of other risk factors (age, leukocyte count, cytogenetic abnormalities, prednisone response), with similar results in children undergoing BM transplantation [26, 27]. To date, translating the utility of MRD assessment in ALL to pediatric lymphoma has been challenging, in part due to access to primary diagnostic tissue in order to identify PSPs as a marker to be used to assess followup specimens. Other challenges include presence or absence of cytogenetic abnormalities such as $13 \mathrm{q}^{-}$and $7 \mathrm{q}^{+}$, which could be useful for prognosis, but there remains a lack of consistent cytogenetic abnormalities other than $c-m y c$ in childhood NHL for use in FISH or PCR [28]. Thus, the current study could potentially be applicable in assessing $\mathrm{PD} / \mathrm{MRD}$ through $\operatorname{IgV}_{\mathrm{H}}$ oligomer pools in a PCR assay that does not rely on primary diagnostic tissue for a specific tumor marker. However there are currently no universally accepted or recognized standard methods to assess $\mathrm{PD} / \mathrm{MRD}$ in pediatric $\mathrm{BL}$ for which to compare. Because the current study is preliminary, emphasis should be placed on the fact that the current assay cannot substitute for the use of PSP-based assay and in the absence of primary diagnostic tissue until further studies are completed.

Other investigators have studied the $\mathrm{IgV}_{\mathrm{H}}$ region in NHL and found preferential $\mathrm{V}_{\mathrm{H}}$ gene usage with $\mathrm{V}_{\mathrm{H} 3}$ and $\mathrm{V}_{\mathrm{H} 4}$ families [8]. For the current study, we screened the primary diagnostic specimens for all of the $V_{\mathrm{H}}$ gene families $\left(\mathrm{V}_{\mathrm{H} 1}\right.$ to $\mathrm{V}_{\mathrm{H} 7}$ ) with the $\mathrm{V}_{\mathrm{H}}$ primer sets and found that, for the limited number of cases, the majority included $\mathrm{V}_{\mathrm{H} 3}$ or $\mathrm{V}_{\mathrm{H} 4}$ families. The data suggest that the PCR assay using $\mathrm{IgV}_{\mathrm{H}}$ primer pools is able to identify B-NHL DNA in clinical specimens, with the limitations as noted above. Clinical translational studies with larger number of patients are needed to assess the utility of this assay to detect PD/MRD and determine the clinical significance. If the assay is validated in larger studies, one of the potential advantages of the tool would be the ease of 


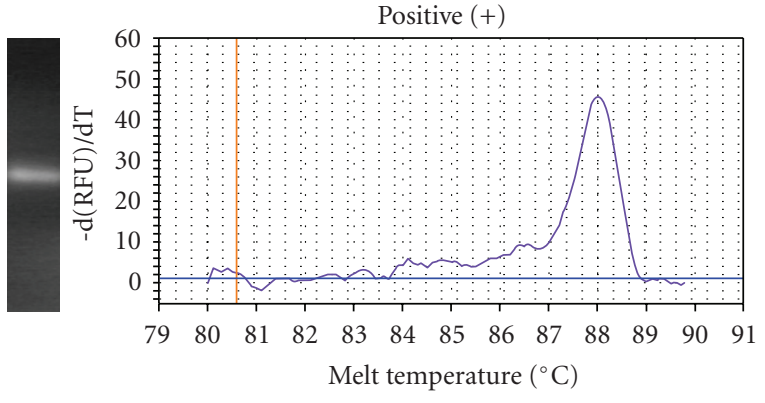

(a)

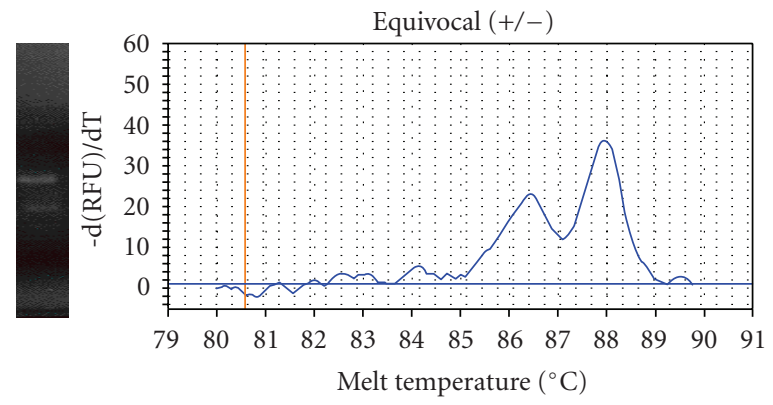

(c)

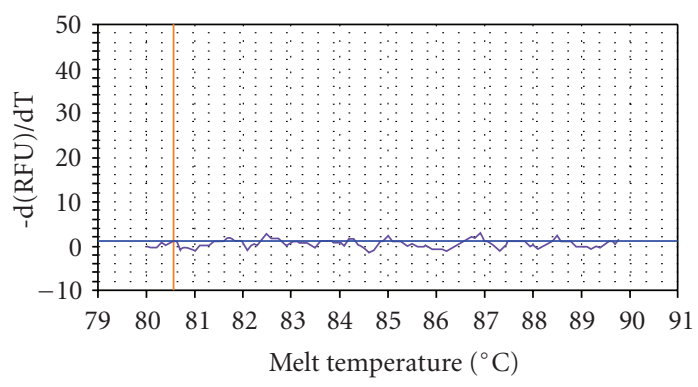

(e)

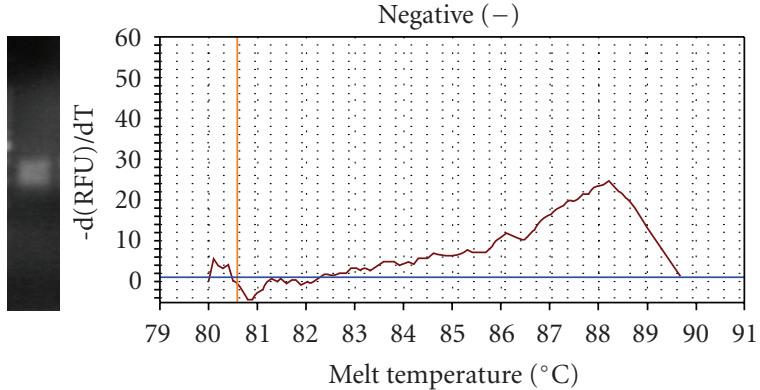

(b)

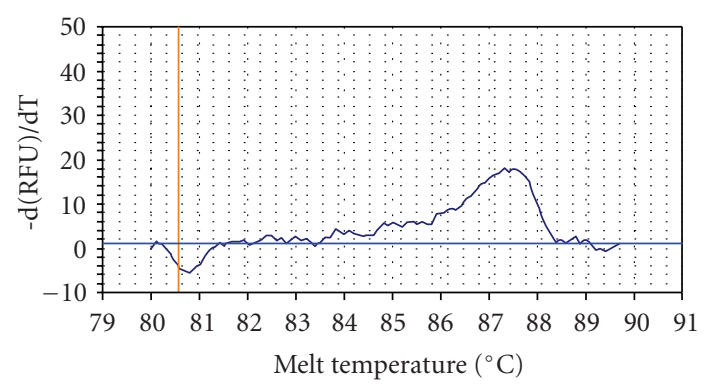

(d)

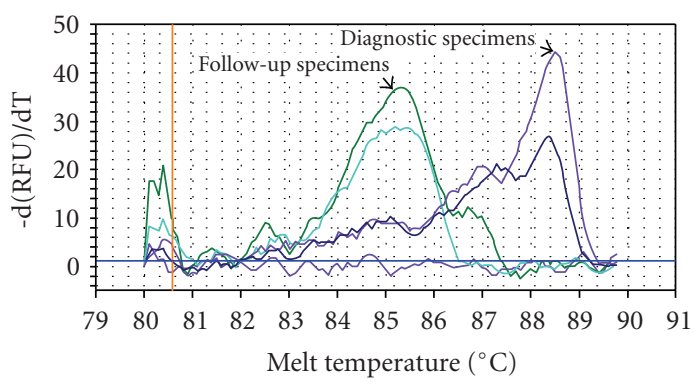

(f)

FIGURE 1: Examples of melt curve analyses with corresponding ethidium-stained amplified products. Melt curves displayed as - dF/dT plots: (a) defined peak with minimal to no shoulder indicates a positive MRD result; (b) a broad peak indicates a negative result; (c) a defined peak with significant shoulders indicates equivocal results. Representative $2.0 \%$ agarose gels are at the left of each of graph. Melt curves of negative controls: (d) PBMC from normal healthy individual shows a broad undefined peak; (e) water (no template) shows no peak; (f) melt curve assessment of PCR products: melt curve peak shift disparities are noted between diagnostic and followup specimens, consistent with possible different clonal differentiation over time.

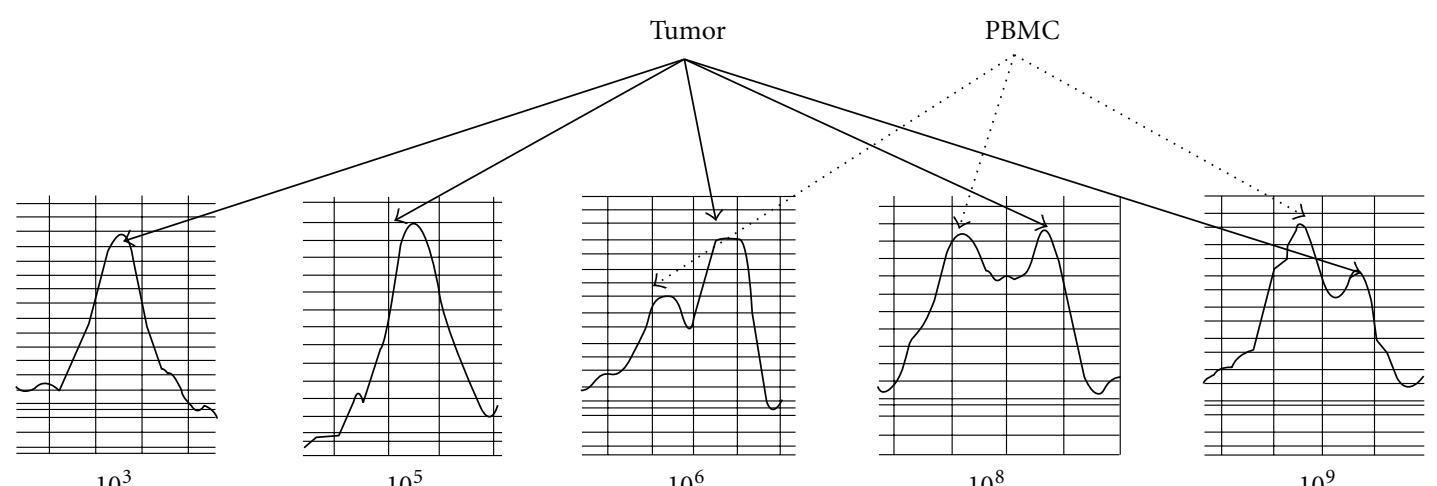

FIGURE 2: MRD sensitivity with patient primary tumor DNA. Primary diagnostic tumor DNA (100\% infiltrated with malignant cells) was diluted with PBMC DNA to represent the equivalent of 1 malignant cell in $10^{3}, 10^{5}, 10^{7}, 10^{8}$, and $10^{9}$ PBMC. Each representative melt curve has a distinct peak corresponding to tumor DNA or PBMC DNA, which are designated by the respective arrows. 
assessing PD/MRD without the need of primary diagnostic tissue.

\section{Acknowledgments}

The authors would like to thank Drs. Ningjie $\mathrm{Hu}$ and Qigui Yu for their technical assistance and members of the Children's Oncology Group NHL Committee. The work was supported in part by NIH/NCI Grant no. CA121955; and the Hawaii Community Foundation Grant no. 20061478.

\section{References}

[1] M. S. Cairo, M. Gerrard, R. Sposto, et al., "Results of a randomized international study of high-risk central nervous system B non-Hodgkin lymphoma and B acute lymphoblastic leukemia in children and adolescents," Blood, vol. 109, no. 7, pp. 2736-2743, 2007.

[2] M. S. Cairo, R. Sposto, S. L. Perkins, et al., "Burkitt's and Burkitt-like lymphoma in children and adolescents: a review of the children's cancer group experience," British Journal of Haematology, vol. 120, no. 4, pp. 660-670, 2003.

[3] C. Patte, A. Auperin, M. Gerrard, et al., "Results of the randomized international FAB/LMB96 trial for intermediate risk B-cell non-Hodgkin lymphoma in children and adolescents: it is possible to reduce treatment for the early responding patients," Blood, vol. 109, no. 7, pp. 2773-2780, 2007.

[4] S. Izraeli and D. Waldman, "Minimal residual disease in childhood acute lymphoblastic leukemia: current status and challenges," Acta Haematologica, vol. 112, no. 1-2, pp. 34-39, 2004.

[5] K. Rajewsky, "Clonal selection and learning in the antibody system," Nature, vol. 381, no. 6585, pp. 751-758, 1996.

[6] G. P. Cook and I. M. Tomlinson, "The human immunoglobulin $\mathrm{V}_{\mathrm{H}}$ repertoire," Immunology Today, vol. 16, no. 5, pp. 237242, 1995.

[7] V. Sabesan, M. S. Cairo, M. A. Lones, et al., "Assessment of minimal residual disease in childhood non-Hodgkin lymphoma by polymerase chain reaction using patient-specific primers," Journal of Pediatric Hematology/Oncology, vol. 25, no. 2, pp. 109-113, 2003.

[8] M. Uchiyama, C. Maesawa, A. Yashima, et al., "Development of consensus fluorogenically labeled probes of the immunoglobulin heavy-chain gene for detecting minimal residual disease in B-cell non-Hodgkin lymphomas," Cancer Science, vol. 94, no. 10, pp. 877-885, 2003.

[9] V. H. J. van der Velden, A. Hochhaus, G. Cazzaniga, T. Szczepanski, J. Gabert, and J. J. M. van Dongen, "Detection of minimal residual disease in hematologic malignancies by realtime quantitative PCR: principles, approaches, and laboratory aspects," Leukemia, vol. 17, no. 6, pp. 1013-1034, 2003.

[10] A. M. O. Shonubi, O. Akiode, B. A. Salami, A. A. Musa, and L. M. Ntele, "A preliminary report of fine-needle aspiration biopsy in superficially accessible lesions in children," West African Journal of Medicine, vol. 23, no. 3, pp. 221-223, 2004.

[11] I. M. Zardawi, "Fine needle aspiration cytology vs. core biopsy in a rural setting," Acta Cytologica, vol. 42, no. 4, pp. 883-887, 1998.

[12] C. A. Wright, J. P. Pienaar, and B. J. Marais, "Fine needle aspiration biopsy: diagnostic utility in resource-limited settings," Annals of Tropical Paediatrics, vol. 28, no. 1, pp. 65-70, 2008.

[13] B. Shiramizu, S. L. Perkins, S. Bergeron, et al., "Assessing immunoglobulin heavy chain rearrangements in pediatric
CD20-positive and CD20-negative classic Hodgkin's disease," Clinical Lymphoma, vol. 5, no. 3, pp. 184-189, 2004.

[14] I. S. Lossos, C. Y. Okada, R. Tibshirani, et al., "Molecular analysis of immunoglobulin genes in diffuse large B-cell lymphomas," Blood, vol. 95, no. 5, pp. 1797-1803, 2000.

[15] K. M. Ririe, R. P. Rasmussen, and C. T. Wittwer, "Product differentiation by analysis of DNA melting curves during the polymerase chain reaction," Analytical Biochemistry, vol. 245, no. 2, pp. 154-160, 1997.

[16] J. A. Nicklas and E. Buel, "Development of an Alu-based, QSY 7-labeled primer PCR method for quantitation of human DNA in forensic samples," Journal of Forensic Sciences, vol. 48, no. 2, pp. 282-291, 2003.

[17] J. A. Nicklas and E. Buel, "Development of an Alu-based, realtime PCR method for quantitation of human DNA in forensic samples," Journal of Forensic Sciences, vol. 48, no. 5, pp. 936944, 2003.

[18] I. U. H. Khan, V. Gannon, R. Kent, et al., "Development of a rapid quantitative PCR assay for direct detection and quantification of culturable and non-culturable Escherichia coli from agriculture watersheds," Journal of Microbiological Methods, vol. 69, no. 3, pp. 480-488, 2007.

[19] G. P. Richards, M. A. Watson, and D. H. Kingsley, "A SYBR green, real-time RT-PCR method to detect and quantitate Norwalk virus in stools," Journal of Virological Methods, vol. 116, no. 1, pp. 63-70, 2004.

[20] A. Varga and D. James, "Real-time RT-PCR and SYBR Green I melting curve analysis for the identification of Plum pox virus strains C, EA, and W: effect of amplicon size, melt rate, and dye translocation," Journal of Virological Methods, vol. 132, no. 1-2, pp. 146-153, 2006.

[21] D. Benjamin, I. T. Magrath, R. Maguire, C. Janus, H. D. Todd, and R. G. Parsons, "Immunoglobulin secretion by cell lines derived from African and American undifferentiated lymphomas of Burkitt's and non-Burkitt's type," The Journal of Immunology, vol. 129, no. 3, pp. 1336-1342, 1982.

[22] D. Xu, X. Du, C. Schultz, A. Ali, and H. Ratech, "Rapid and accurate detection of monoclonal immunoglobulin heavy chain gene rearrangement by DNA melting curve analysis in the lightcycler system," Journal of Molecular Diagnostics, vol. 4, no. 4, pp. 216-222, 2002.

[23] C. J. Chapman, D. Wright, and F. K. Stevenson, "Insight into Burkitt's lymphoma from immunoglobulin variable region gene analysis," Leukemia and Lymphoma, vol. 30, no. 3-4, pp. 257-267, 1998.

[24] J. Z. Gong, T. T. Stenzel, E. R. Bennett, et al., "Burkitt lymphoma arising in organ transplant recipients: a clinicopathologic study of five cases," American Journal of Surgical Pathology, vol. 27, no. 6, pp. 818-827, 2003.

[25] J. Zhou, M. A. Goldwasser, A. Li, et al., "Quantitative analysis of minimal residual disease predicts relapse in children with B-lineage acute lymphoblastic leukemia in DFCI ALL Consortium Protocol 95-01," Blood, vol. 110, no. 5, pp. 1607$1611,2007$.

[26] A. Biondi, M. G. Valsecchi, T. Seriu, et al., "Molecular detection of minimal residual disease is a strong predictive factor of relapse in childhood B-lineage acute lymphoblastic leukemia with medium risk features. A case control study of the international BFM study group," Leukemia, vol. 14, no. 11, pp. 1939-1943, 2000.

[27] C. J. C. Knechtli, N. J. Goulden, J. P. Hancock, et al., "Minimal residual disease status as a predictor of relapse after allogeneic bone marrow transplantation for children with acute 
lymphoblastic leukaemia," British Journal of Haematology, vol. 102, no. 3, pp. 860-871, 1998.

[28] H. A. Poirel, A. Bernheim, A. Schneider, et al., "Characteristic pattern of chromosomal imbalances in posttransplantation lymphoproliferative disorders: correlation with histopathological subcategories and EBV status," Transplantation, vol. 80, no. 2, pp. 176-184, 2005. 


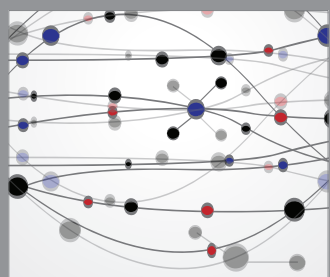

The Scientific World Journal
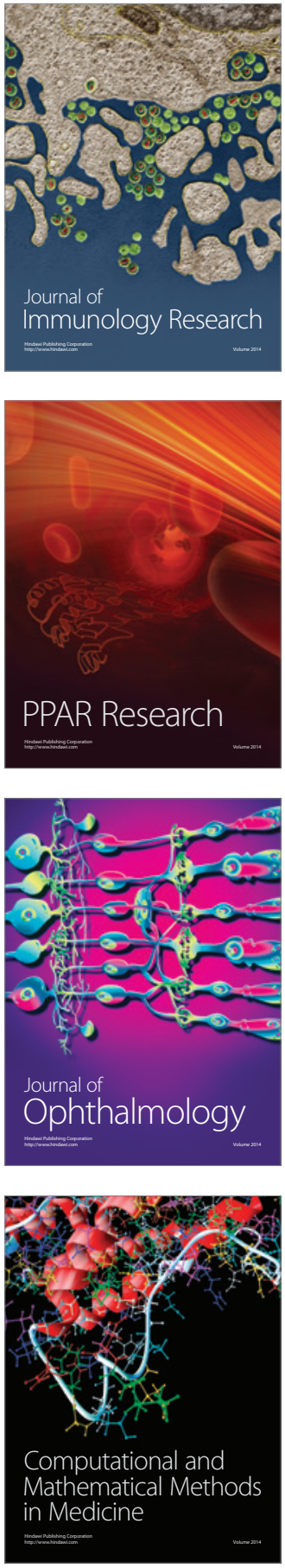

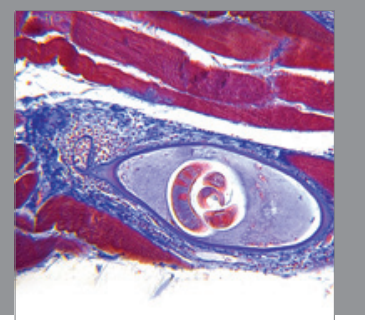

Gastroenterology

Research and Practice
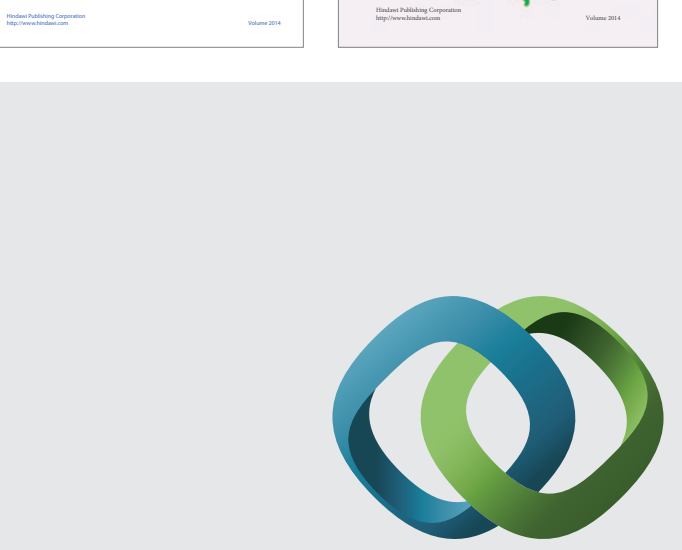

\section{Hindawi}

Submit your manuscripts at

http://www.hindawi.com
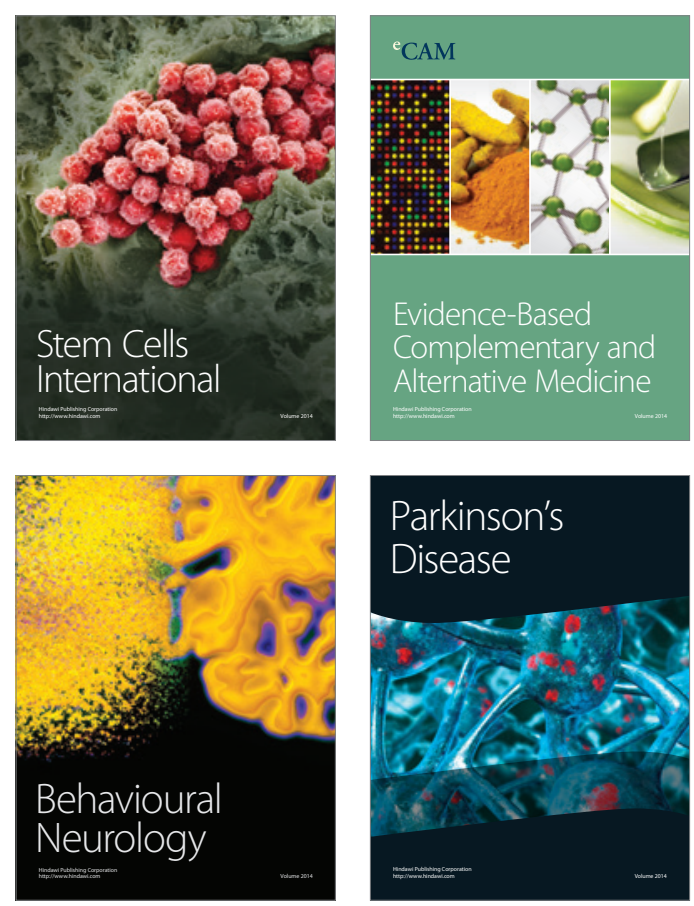

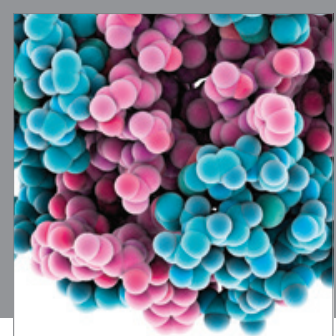

Journal of
Diabetes Research

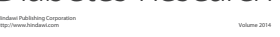

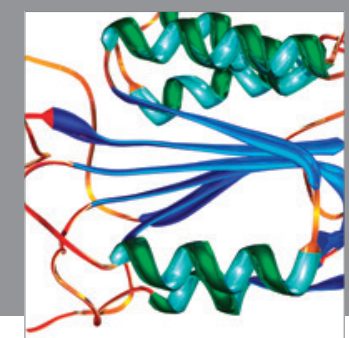

Disease Markers
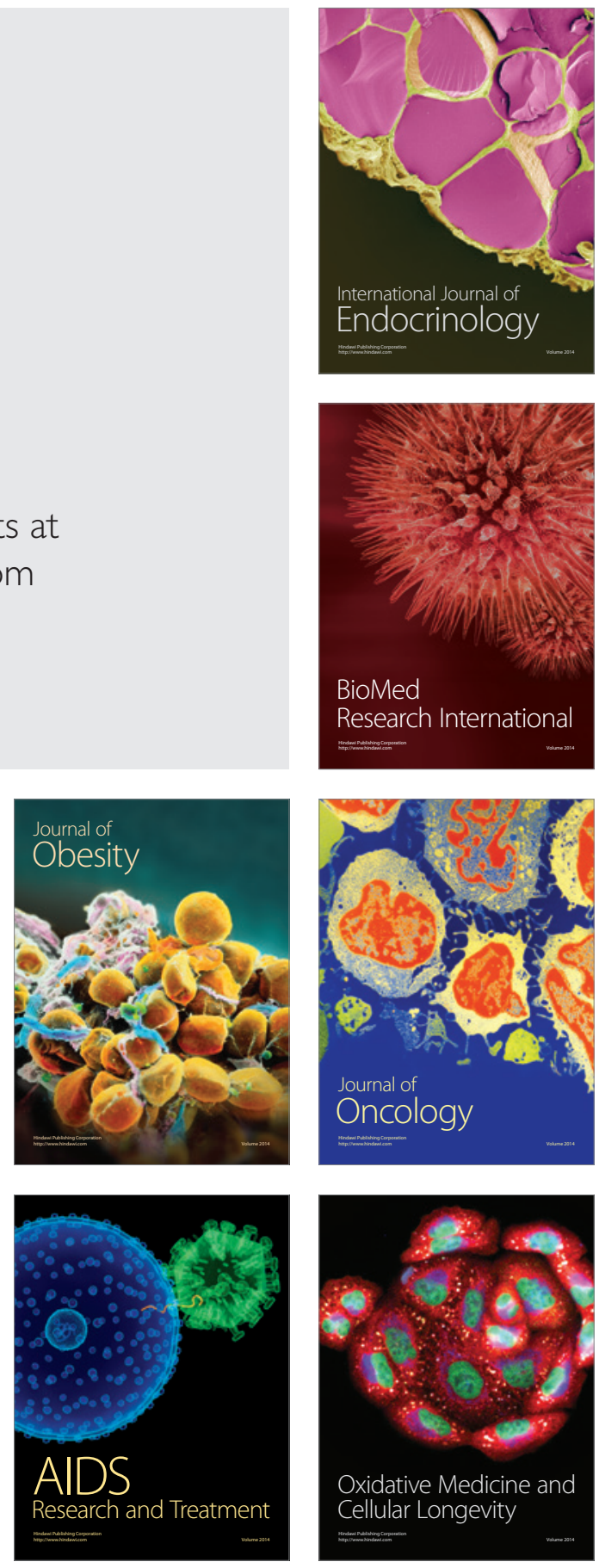